\title{
Molecular Detection of Human Papilloma Virus Type 16 among Conjunctival Intraepithelial Neoplasia Patients in Khartoum State, Sudan
}

\author{
Hala H Ahmed ${ }^{1}$, Aya A Almtry ${ }^{1}$, Isra M Aidrous ${ }^{1}$, Sara M Ali ${ }^{1}$, Mohamed H Arbab ${ }^{2}$ and Ali M Badri ${ }^{*}$ \\ ${ }^{1}$ Department of Microbiology, Faculty of Medical Laboratory Sciences, International University of Africa, \\ Khartoum, Sudan \\ ${ }^{2}$ Department of Microbiology, Faculty of Medical Laboratory Sciences, Omdurman Ahlia University, \\ Khartoum, Sudan
}

*Corresponding author: Ali M Badri, Department of Microbiology, Faculty of Medical Laboratory Sciences, International University of Africa, Khartoum, Sudan

\begin{abstract}
Many factors like exposure to UV radiation, climatic conditions, genetic predisposition, immunological state and, more recently, the presence of HPV have been implicated in the genesis of some lesions of the conjunctiva, especially the carcinoma. The study was carried out to detect Human Papilloma Viruses HPV type 16 in conjunctival intraepithelial neoplasia patient in Khartoum state, Sudan during the period from March to July 2019. A total of 50 Formalin-fixed paraffin-embedded Samples were collected from conjunctival intraepithelial neoplasia patients attending the Radiation-Isotopes Centre, Khartoum, Sudan by using polymerase chain reaction. Out of 50 patients $30(60 \%)$ males and $20(40 \%)$ females, with a mean age of 38 years, in range from 15-70 years. The result showed 7 (14\%) was positive for HPV-16 and $43(86 \%)$ were negative. Our results show that HPV-16 infection is associated with conjunctival intraepithelial neoplasia, but does not act alone in the development of conjunctival epithelial neoplasia. However, additional studies with a larger number of samples will be necessary.
\end{abstract}

\section{Keywords}

Conjunctival epithelial neoplasia, HPV-16, Molecular Identification

\section{Introduction}

Papillomaviruses are small, non-enveloped, epitheliotropic, double stranded DNA viruses that infect mucosal and cutaneous epithelia in a wide variety of higher vertebrates in a species-specific manner and induce cellular proliferation. HPVs have been identified in association with a variety of benign and malignant epithelial lesions ranging from common cutaneous warts, respiratory papillomatosis, pterygium, and papilloma of the conjunctiva to an expanding epidemic of sexually transmitted anogenital condyloma and cervical cancer $[1,2]$. The potential for malignant transformation of some HPV is related to its ability to bind tumor suppressor proteins in the host, thus affecting the cellular cycle of the infected cells [3]. The HPV already identified in the conjunctiva are of the high risk types 16 and 18 and the low risk types 6 and $11[4,5]$. Family history, age, ethnic origin, environment and genetic factors are the only firmly established risk factors for cancer. The conjunctiva is the clear, thin membrane that covers part of the front surface of the eye and the inner surface of the eyelids. It has two segments includes Bulbar conjunctiva, which it's the portion of the conjunctiva covers the anterior part of the sclera (the "white" of the eye). The bulbar conjunctiva stops at the junction between the sclera and cornea; it does not cover the cornea and the Palpebral conjunctiva that covers the inner surface of both the upper and lower eyelids. The first demonstration of HPV in the conjunctiva was in the 1980's. Earlier studies have implicated HPV infection in the pathogenesis of conjunctival papillomas because of the frequent finding of koilocytotic features in these lesions. More 
recently, the presence of HPV capsid antigens and DNA sequence has been documented in conjunctival neoplasms, including papillomas, dysplasia, and squamous cell carcinomas $[6,7]$. However, the frequency of HPV DNA detection in the conjunctiva varies considerably [4]. The aim of our study to assess the frequency of HPV type 16 in different grades of conjunctival intraepithelial neoplasia in order to prevent this disease.

\section{Materials and Methods}

\section{Study design}

A cross-sectional descriptive study was carried out in the period from March to July 2019 involving a group consisted of 50 conjunctival cancer patients ( $60 \%$ male and $40 \%$ female) attended department of histopathology in KRIC in Khartoum State, Sudan. The patients' ages ranged from 15 to 70-years-old. The demographic data collected included Patient number, Name, age, gender, residence, metastasis, site of biopsy, tumor histology, tumor grade, as lymph vascular invasion, surgical margin. Samples (Paraffin embedded tissues) were collected from the KRIC. Paraffin-embedded formalin-fixed tissues were collected from these patients and tested for the presence of HPV16 DNA using conventional PCR in the Molecular Biology Research Lab, International University of Africa in Khartoum State, Sudan. Ethical approved by the KRIC committee, International University of Africa, Faculty of medical laboratory sciences, Department of Microbiology. For collecting the samples and all patients included in this study was told for the study purpose and asked for agreement and verbal consent was obtained.

\section{Sample collection}

A total of 50 Formalin-fixed paraffin-embedded Samples were collected from conjunctival cancer patients attended KRIC. From each patient, the sample collection involved 8 cuts each one of 10 um thickness which collected in sterile Eppendroff's tube containers and kept at RT until used.

\section{Laboratory Work and Protocols}

\section{DNA Extraction}

DNA was extracted from 8 cuts of paraffin embedded tissue sample each one of $10 \mu \mathrm{m}$, following DNA extraction with Guanidine method. $2 \mathrm{ml}$ of WBC lysis buffer was added to tissues in falcon tube and incubated at $98{ }^{\circ} \mathrm{C}$ for 15 minutes then vortex and left to cool. 10 $\mu \mathrm{l}$ of proteinase $\mathrm{k}$ was added with gentle vortexing and incubated at $56 \mathrm{c}$ overnight. On second day the mixture was vortexed and cooled, $10 \mu \mathrm{l}$ of proteinase $\mathrm{k}$ was added and vortexed gently then incubated at 65 c overnight. on third day, $1 \mathrm{ml}$ of guanidine and $300 \mu \mathrm{l}$ of ammonium acetate was added and incubated at $65 \mathrm{c}$ for $1 \mathrm{~h} 30 \mathrm{~min}-$ utes then vortexed gently and cooled at RT. $2 \mathrm{ml}$ of cold chloroform was added to the tube (to precipitate the protein down and the DNA remain in the aqueous layer) then vortexed and centrifuged at (3000-6000 rpm) for 57 minutes, two layers appeared. The aqueous phase (upper layer) was transferred carefully to clean falcon tube, and to which 3 times volume of cold absolute ethanol was added to precipitate the DNA then shaked incubated over night at $-20{ }^{\circ} \mathrm{C}$. on $4^{\text {th }}$ day The tube was centrifuged $6000 \mathrm{rpm}$ for 10-15 minutes. The supernatant was poured off without disturbing the precipitate, and then washed with $4 \mathrm{ml}$ of $70 \%$ ethanol (Rehydration). The tube content was centrifuged at $6000 \mathrm{rpm}$ for 10-15 minutes, the ethanol was discarded and the tube is left to air dry. The pellets were suspended in $50 \mu \mathrm{l}$ deionized water or TE (buffer EDTA chelates any $\mathrm{Mg}^{2+}$ helping to inactivate DNases) then vortexed and left to dissolve at $4 \mathrm{c}$ overnight and stored at $-20^{\circ} \mathrm{C}$ until tested.

\section{Detection of HPV16 DNA by using PCR}

PCR was performed and the test was carried out using following primers: forward: 5-ACCCAGTATAGCTGACAGT-3 and reverse: 5-CTCGTTTATAATGTCTACACA-3. Each reaction was performed in total volume of $25 \mu \mathrm{l}$, containing $5 \mu \mathrm{l}$ master mix (Solis Bio dyne master mix), $2 \mu$ l of primer, $5 \mathrm{ng} / \mu \mathrm{g}$ of DNA and $13 \mu \mathrm{l}$ of distilled water. The PCR was performed for 35 cycles at $94{ }^{\circ} \mathrm{C}$ for 1 min for denaturation, $49{ }^{\circ} \mathrm{C}$ for $1 \mathrm{~min}$ for annealing and $72{ }^{\circ} \mathrm{C}$ for $1 \mathrm{~min}$ for extension; the final extension at $72{ }^{\circ} \mathrm{C}$ for $7 \mathrm{~min}$ [8]. $5 \mu \mathrm{l}$ of the PCR product was analyzed using 1\% Agarose gel electrophoresis, and stained with $0.15 \%$ Ethidium bromide and the product was visualized using UV gel documentation system. The expected size of HPV 16DNA amplicon is $512 \mathrm{bp}$.

\section{Data analysis}

The Statistical Package for Social Sciences (SPSS 25) was used for statistical analysis.

\section{Results}

A total of 50 Formalin-fixed paraffin-embedded Samples were analyzed to determine the prevalence of Human Papilloma Virus Type 16 (HPV-16) among Sudanese conjunctival intraepithelial neoplasia patients attending the Radiation-Isotopes Centre, Khartoum, Sudan by using polymerase chain reaction. Out of 50 patients selected $30(60 \%)$ males and $20(40 \%)$ females, with a mean age of 38 years, in range from 15-70 years. The result showed that out of 50 Forma-

Table 1: Frequency of HPV-16 DNA among Sudanese conjunctival intra-epithelial neoplasia patients according gender.

\begin{tabular}{|l|l|l|l|}
\hline \multirow{2}{*}{ Gender } & HPV -16 DNA & Total (\%) \\
\cline { 2 - 3 } & Positive (\%) & Negative (\%) & \\
\hline Male & $5(10 \%)$ & $25(50 \%)$ & $30(60 \%)$ \\
\hline Female & $2(4 \%)$ & $18(36 \%)$ & $20(40 \%)$ \\
\hline Total & $7(14 \%)$ & $43(86 \%)$ & $50(100 \%)$ \\
\hline
\end{tabular}




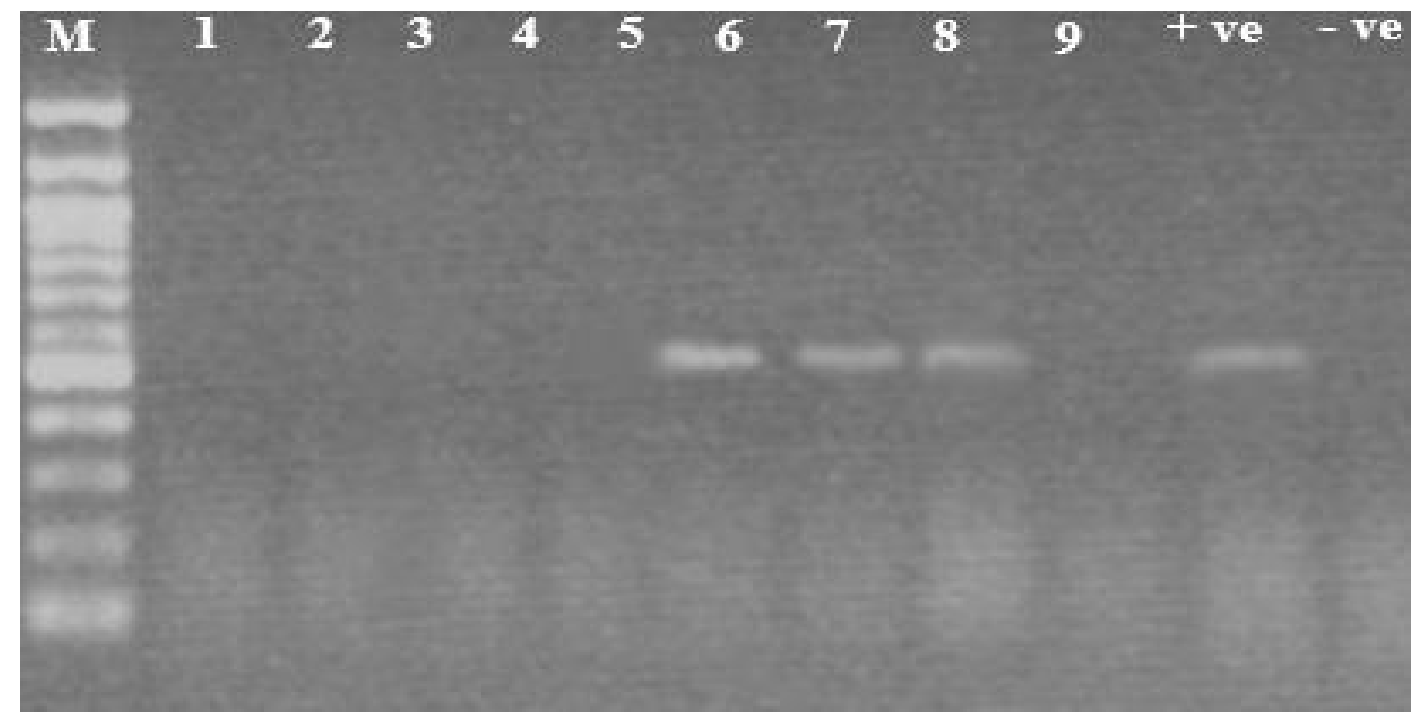

Figure 1: HPV-16 DNA results (512bp) on 1.5\% agarose gel. Lane M shows 100 bp DNA marker, lane 11 shows negative control, lane 10 shows positive control, lanes 1, 2, 3, 4, 5 and 9 show negative results, lanes 6,7 and 8 show positive results.

lin-fixed paraffin-embedded Samples investigated, 7 (14\%) was positive for HPV-16 and 43 (86\%) were negative (Table 1 and Figure 1).

\section{Discussion}

Overall, this study suggests that mucosal and EV HPVs do infect the conjunctival epithelium, but does not confirm a role for specific HPVs in the development of conjunctival carcinoma. HPV has been established as a significant cofactor in genital carcinogenesis. For upper aero digestive tract carcinomas, there is controversy about the incidence of HPV infection and its possible significance as an oncogenic cofactor. It is assumed that the association between HPV and malignant transformation is related to the interaction of cellular proteins and tumor suppressor genes. The detection of HPV in the apparently healthy mucosa has previously been reported in the literature from different anatomical locations such as the cervix and larynx, as well as the conjunctiva $[5,9,10]$. The latency of the virus can be demonstrated by the detection of HPV DNA in the mucosa in the absence of clinical lesions and subclinical changes [11]. About 15 to $40 \%$ of women with positive HPV in the cervix do not have any kind of mucosal change $[12,13]$. In the conjunctiva, investigators have identified HPV DNA 16 in swabs from clinically uninvolved eyes and have also reported persistent infection by HPV for many years after successful eradication of epithelial neoplasia, without any recurrences [5]. The significance and the implications of virus latency in the conjuncti$v a$, as in other mucosa, need additional investigation. The modes of HPV transmission, depending on the HPV type and location, may involve casual physical contact, sexual contact and perinatal vertical transmission. The access of HPV to the conjunctiva is still an object of investigation. Transmission to the conjunctiva may occur as a result of fetal passage through an infected birth canal or by ocular contact with contaminated hands or objects [14]. The former mechanism could easily explain the conjunctival papillomas found in children, but not necessarily those of adults. Our study which Evaluated the possible existence of HPV16 genome in Conjunctival Neoplasia demonstrated that despite the high sensitivity of conventional PCR methods, out of 50 patients selected $30(60 \%)$ males and $20(40 \%)$ females, the result showed that out of 50 Formalin-fixed paraffin-embedded Samples investigated, 7 (14\%) was positive for HPV-16 and 43 (86\%) were negative. Earlier studies have demonstrated a close linkage between conjunctival papillomas and HPV-16 were carried out by McDonnell 1989 and Saegusa 1995 [15,16]. We used the PCR technique in our study because it shows the most sensitivity of all the available methods. Also has been widely used over recent years for the detection of HPV in cutaneous and mucosal lesions [17].

\section{Conclusion}

The etiopathogenic role of HPV-16 in the conjunctiva is yet to be established. Our results show that HPV-16 infection is associated with conjunctival intraepithelial neoplasia, but does not act alone in the development of conjunctival epithelial neoplasia. However, additional studies with a larger number of samples will be necessary.

\section{References}

1. Zur Hausen H (1999) Papillomaviruses in human cancers. Proc Assoc Am Physicians 111: 581-587.

2. Sun EC, Fears TR, Goedert JJ (1997) Epidemiology of squamous cell conjunctival cancer. Cancer Epidemiol Biomarkers Prev 6: 73-77.

3. Bernard HU, Chan SY, Manos MM, Ong CK, Villa LL, et al. (1994) Identification and assessment of known and novel papillomavirus by polymerase chain reaction amplification, restriction fragment length polymorphism, nucleotide sequence and phylogenetic algorithms. J Infect Dis 170: 1077-1085. 
4. International Agency for Research on Cancer- IARC (1995) Evaluation of carcinogenic risks to humans: human papillomaviruses. Lyon: IARC (IARC Monographs, v.64).

5. McDonnell JM, McDonnell PJ, Sun YS (1992) Human papillomavirus DNA in tissues and ocular surface swabs of patients with conjunctival epithelial neoplasia. Invest Ophthalmol Vis Sci 33: 184-189.

6. McDonnell JM, McDonnell PJ, Mounts P, Wu TC, Green WR (1986) Demonstration of papillomavirus capsid antigen in human conjunctival neoplasia. Arch Ophthalmlol 104: 1801-1805.

7. Odrich MG, Jakobiec FA, Lancaster WD, Kenyon KR, Kelly LD, et al. (1991) A spectrum of bilateral squamous conjunctival tumor associated with human papillomavirus type 16 . Ophthalmology 98: 628-635.

8. Raji N, Sadeghizadeh M, Tafreshi KN, Jahanzad E (2011) Detection of human Papillomavirus 18 in cervical cancer samples using PCR-ELISA (DIAPOPS). Iranian Journal of Microbiology 3: 177-182.

9. Villa LL, Franco EL (1989) Epidemiological correlates of cervical neoplasia and risk of human papillomavirus infection in asymptomatic women in Brazil. J Natl Cancer Inst 81: 332-340.

10. Brandsma JL, Lewis AJ, Abramson A, Manos MM (1990) Detection and typing of papillomavirus DNA in formalde- hyde-fixed paraffinembedded tissue. Acta Otolaryngol Head Neck Surg 116: 844-848.

11. Alberts B, Bray D, Lewis J, Roberts K, Watson JD (1989) Molecular biology of the cell. New York: Garland 12031212.

12. Reid R, Stanhope R, Herschman BR, Booth E, Phibbs GD, et al. (1992) Genital warts and cervical cancer: I. Evidence of an association between subclinical papillomavirus infection and cervical malignancy. Cancer 50: 377-387.

13. Villa LL (1995) Papilomavírus humano e câncer de colo do útero. Laes \& Haes 97: 60-67.

14. Bailey RN, Guethlein ME (1990) Diagnosis and management of conjunctival papillomas. J Am Optom Assoc 61: 405-412.

15. McDonnell JM, Mayr AJ, Martin WJ (1989) DNA of human papillomavirus type 16 in dysplastic and malignant lesions of the conjunctiva and cornea. N Engl J Med 320: 14421446.

16. Saegusa M, Takano Y, Hashimura M, Okayasu I, Shiga J (1995) HPV type 16 in conjunctival and junctional papilloma, dysplasia, and squamous cell carcinoma. J Clin Pathol 48: 1106-1110.

17. Munoz N, Castellsagué $X$, de González AB, Gissmann L (2006) HPV in the etiology of human cancer. Vaccine 24: S1-S10. 